\title{
Characterizing Vegetation Response to Climatic Variations in Hovsgol, Mongolia Using Remotely Sensed Time Series Data
}

\author{
Thuan $\mathrm{Chu}^{1} \&$ Xulin Guo ${ }^{1}$ \\ ${ }^{1}$ Department of Geography and Planning, University of Saskatchewan, Saskatoon, Canada \\ Correspondence: Xulin Guo, Department of Geography and Planning, University of Saskatchewan, Kirk Hall, \\ 117 Science Place, Saskatoon, SK S7N5C8, Canada. Tel: 1-306-966-5663. E-mail: xulinguo@gmail.com
}

Received: June 29, 2012 Accepted: July 9, 2012 Online Published: July 25, 2012

doi:10.5539/esr.v1n2p279 URL: http://dx.doi.org/10.5539/esr.v1n2p279

\begin{abstract}
One of the challenges faced by forest managers is the inability to quickly interpret forest ecosystem attributes and vegetation responses to climate change. This research aims to address this challenge by characterizing the phenological metrics and evaluating the temporal and spatial dynamics of vegetation over 12 years (2000-2011) under climate change effects in Hovsgol, Mongolia. Time series Normalized Difference Vegetation Index (NDVI) was used as an indicator to monitor vegetation response in the area. The effects of climatic variations on vegetation growth were considered through the relationship between climatic variables and NDVI. Results indicate that the growing season commonly starts in late April and ends in late October with full growth by July, and as a consequence of climate change in the area, the growing season in recent years seems to be beginning earlier. Plant stress caused by higher temperature was the most significant contributor to earlier vegetation green up since NDVI, length, and starting point of the growing season strongly depend on air temperature. Analysis of spatio-temporal heterogeneity indicates some areas with highly dynamic NDVI, particularly in the western part of the Hovsgol Lake, the high mountainous areas, and the Darhad valley. Our results suggest that temperature variations mainly determine the pattern of vegetation responses in the Hovsgol area.
\end{abstract}

Keywords: climatic variation, NDVI, phenological metrics, vegetation response

\section{Introduction}

The climate of Mongolia has undergone significant changes over the last few decades. Batima et al. (2005) reported that Mongolia's average temperature has increased by $1.7^{\circ} \mathrm{C}$ since the $1940 \mathrm{~s}$, while the precipitation has tended to decrease slightly. The temperature is predicted to increase by $2^{\circ} \mathrm{C}$ in summer and $1{ }^{\circ} \mathrm{C}$ in winter during the next 80 years (Sato et al., 2006). These changes are the likely causes of the summer droughts and directly affect vegetation growth, biodiversity, and human socioeconomics in Mongolia (Batima et al., 2005; James, 2011; Yu et al., 2003). The results of tree-ring analyses of single areas in Mongolia (Dulamsuren et al., 2010; James, 2011) suggest that forests generally respond to global warming with very high variations depending on the regional variations of temperature, precipitation, and land cover types.

Some recent studies in Mongolia have explored the use of time-series remotely sensed data to investigate vegetation response to climatic variation and other disturbances such as wildfires. Erdenesaikhan (2002) used National Oceanic and Atmospheric Administration (NOAA) Advanced Very High Resolution Radiometer (AVHRR) time series data from 1991 to 2001 to estimate vegetation greenness and variation based on Normalized Difference Vegetation Index (NDVI) for the entirety of Mongolia. The result showed that there were high spectral and greenness variations in the northern part of the country, including the high mountains and taiga forest during the maximum vegetation growing seasons in Mongolia (July to August). Yu et al. (2003, 2004) examined the seasonal vegetation response to climatic variations on the Mongolia steppes using time series analysis of AVHRR NDVI data, and proposed that the taiga forest of the northern Mongolia steppes experienced an earlier onset of green up. The authors assumed that the precipitation was the most significant factor determining the pattern of vegetation responses to global warming. Other studies in Mongolia related to active forest and steppe fires detection by using thermal infrared NOAA AVHRR bands (IFFN, 1999; Magsar Erdenetuya, 1999; Sanjaa Tuya, 2002).

There are a number of studies around the world which have successfully applied remote sensing techniques not only in identifying disturbance events, but also in vegetation trajectory responses in which NDVI is the most 
common indicator to characterize vegetation responses (i.e. Zhang et al., 2008; Leon et al., 2012; Van Leeuwen, 2008; Van Leeuwen et al., 2010; Veraverbeke et al., 2011; Yang, 2011; Yu et al., 2003; 2004). Seasonal phenometrics of vegetation extracted from NDVI have been focused on to compare rates of change and length of growing season influenced by climate change or fire (Casady et al., 2009; Van Leeuwen et al., 2010). Additionally, a departure of NDVI from average (Erdenesaikhan, 2002; Van Leeuwen, 2008), standard deviation (SD), and coefficient of variation (COV) (Zhang et al., 2008; Guo, 2004; Van Leeuwen et al., 2010) have been widely used to estimate vegetation heterogeneity and dynamics caused by disturbances.

To date, however, very few studies in Mongolia and particularly in Hovsgol area have been conducted to identify seasonal phenology and detect both temporal and spatial changes of forest influenced by climate change using remote sensing. Under the assumption that NDVI is an effective surrogate for forest status, therefore, the objectives of this study are to: 1) extract phenological parameters and characterize the temporal and spatial variation of vegetation covers in the Hovsgol area from 2000 to 2011; and 2) evaluate the relationship between climate variations and vegetation responses in Hovsgol during the study period. More specifically, temporal and spatial vegetation dynamics and phenological metrics of vegetation growth were assessed based on time series NDVI data over 12 years (2000-2011). Air temperature and precipitation are two climatic variables to evaluate climate change effects on vegetation during the study period.

\section{Data and Methods}

\subsection{Study Area}

The study was conducted in Hovsgol province, the northern part of Mongolia $\left(49^{\circ} 38^{\prime} \mathrm{N}, 100^{\circ} 10^{\prime} \mathrm{E}\right)$ (Figure 1). Hovsgol province is the most densely forested area in Mongolia with $31781 \mathrm{sq} \mathrm{km}$ of closed forest accounting for 30\% of Mongolia's total closed forest area (James, 2011). The Siberian larch (Larix Siberica) dominantly contributes more than $90 \%$ to the forest composition in the area. The average temperatures during winter range from $-16.5^{\circ} \mathrm{C}$ to $-23.0^{\circ} \mathrm{C}$ with an extreme minimum of $-47.7^{\circ} \mathrm{C}$ recorded in January 2000 , while average summer temperatures range from $10.8^{\circ} \mathrm{C}$ to $11.8^{\circ} \mathrm{C}$ with the highest temperature of $31.6^{\circ}$ recorded in July 2002 (Murray, 2004). The region is experiencing major climate change illustrated by the $1.8^{\circ} \mathrm{C}$ annual temperatures increase over the last 40 years (1963-2002) (Banzragch, 2007). Additionally, the forest area was heavily affected by wildfire in 1996 and 2000-2002 (Farukh et al., 2009; IFFN, 2007).

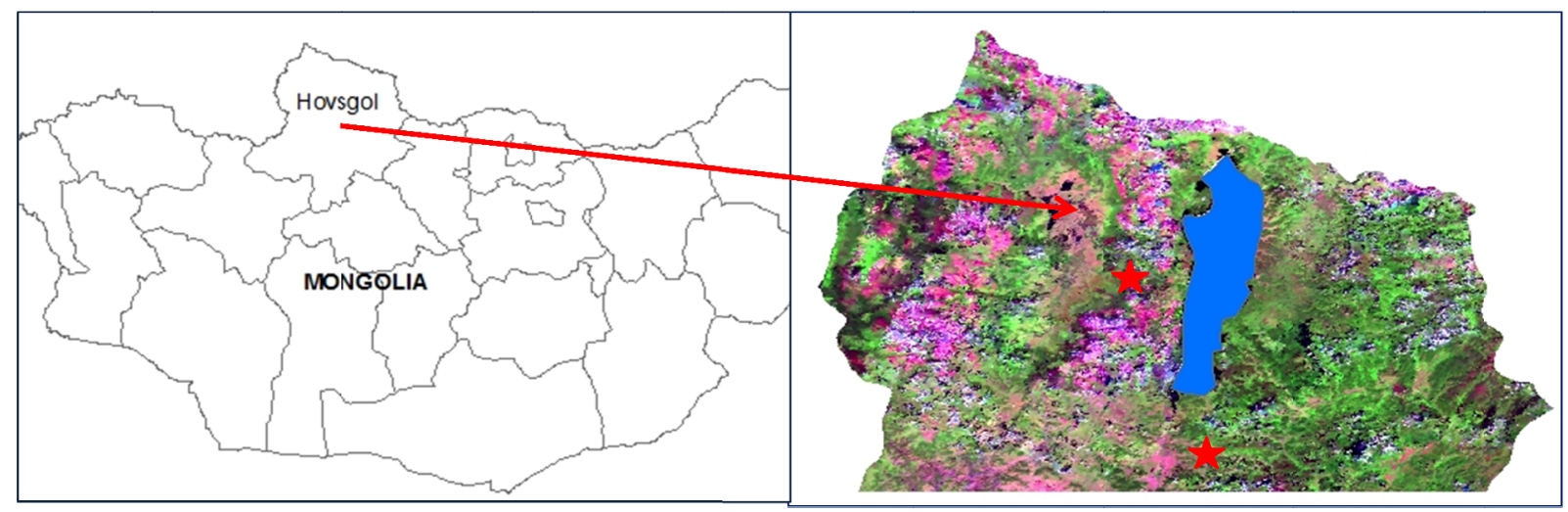

Figure 1. Study area in Hovsgol province, Mongolia; July, 2000 MODIS data in Hovsgol area (right); weather station

\subsection{MODIS Time Series Data and Climatic Variables}

This study examined the use of $250 \mathrm{~m}$ spatial resolution, 16 day MODIS NDVI (MOD13Q1), and $1000 \mathrm{~m}$ spatial resolution, 8 day MODIS Land Surface Temperature (LST) (MOD11A2) time series data to evaluate vegetation dynamics and its response to climate variations using some of the methods in the literature. These MODIS time series data during the growing season (April to October) were obtained for the study area from the NASA website http://reverb.echo.nasa.gov. Statistical parameters (i.e. mean NDVI, LST, NDVI coefficient of variation) were calculated from these time series data.

For the purpose of extracting phenological metrics and in order to reduce calculation work, we only used subset of the 16 day MODIS NDVI data (100x100km; 51.52N, 98.92E) from January to December, 2000-2011, which 
was downloaded from the website http://daac.ornl.gov/MODIS/modis.html. This resulted in 23 subsets of $250 \mathrm{~m}$ spatial resolution, 16 day MODIS NDVI images each year, except for the three missing NDVI images between January and February, 2000. The subset was selected as a representative for the entire area to extract phenological parameters.

Air temperature is commonly used to analyze climatic conditions within a geographic extent (Ravenscroft et al., 2010; Vancutsem et al., 2010). Monthly mean maximum air temperature and monthly sum precipitation in Hatgal $(50.4 \mathrm{~N}, 100.2 \mathrm{E})$ and Rinchinlhumble $(51.1 \mathrm{~N}, 99.7 \mathrm{E})$ weather stations in Hovsgol province were downloaded from the Weather Underground website http://www.wunderground.com. However, due to the insufficiency of these data from January 2000 to May, 2004, this study estimated missing monthly air temperature based on the Temperature Vegetation Index (TVX) method (Nieto et al., 2011; Prihodko et al., 1997). This approach derives air temperature based on the correlation between LST and NDVI.

\subsection{Data Analysis Approach}

\subsubsection{Preprocessing}

All downloaded MODIS LST and MODIS NDVI time series data in sinusoidal projection were reprojected into the UTM projection using MRTtools (USGS, 2011). $1 \mathrm{~km}$ spatial 8 day MODIS LST was resampled to $250 \mathrm{~m} 16$ day MODIS LST data in order to be compatible with the $250 \mathrm{~m} 16$ day MODIS NDVI data. This preprocessing resulted in a time series of 336 MODIS images (168 NDVI and 168 LST) during the study area's growing season over 12 years. Following this preprocessing, 150 sample sites were then randomly selected in the time series images to collect LST and NDVI samples for the statistical descriptions and models calibration. For the subset MODIS data representing the study area, mean NDVI for each 16 day period from January to December over 12 years was extracted to derive phenological metrics.

\subsubsection{Estimation of Air Temperature Using the TVX Method}

Corresponding with observed air temperature from 2004 to 2011 at Rinchinlhumbe weather station, land surface temperature and NDVI were collected to derive the TVX regression model. Air temperature at pixel level for the entire area can be estimated using the equation below (2.1). The model was validated by the measured air temperature at Hatgal weather station with a mean absolute error of $2 \cdot 2^{\circ} \mathrm{C}\left(\mathrm{RMSE}=2.4^{\circ} \mathrm{C}\right)$. Compared with the other studies from the literature review (i.e. Nieto et al., 2011; Vancutsem et al., 2010), this error is acceptable to estimate air temperature at any location based on land surface temperature and NDVI values.

$$
\text { Tair }=23.24 * \text { NDVI }+0.307 * \text { LST }-2.96\left(\mathrm{R}^{2}=0.89, \text { Adjusted } \mathrm{R}^{2}=0.88, \mathrm{p}<0.001\right)
$$

The study used climatic variables including temperature and precipitation employed at Rinchinlhumbe weather station for the assessment of climate change effects since this station is located near Darhad valley in the centre of the study area. Missing air temperature from 2000 to 2004 in the Rinchinlhumbe station was estimated using the TVX equation above.

\subsubsection{Extracting Phenological Metrics}

Onset and end of growing season were decided by analyzing NDVI time series data based on curve derivative methods in the TIMESAT software (Jonsson et al., 2002; 2004). For the analysis of seasonal and interannual vegetation dynamics, this technique facilitates the evaluation of variability and trends of vegetation phenology in relation to climate change and disturbances (Jonsson \& Eklundh, 2004). All monthly extracted mean NDVI data during January to December (2000-2011) from the subset MODIS data were imported into the software to identify the onset and end of the growing season each year. The Savitsky-Golay curve derivative method was used to describe vegetation phenometrics for the area (Figure 2). The start and end of the growing season was defined as the point in time for which the NDVI value had increased by $20 \%$ of the distance between the minimum NDVI value and the maximum NDVI value (Zhang et al., 2008; Van Leeuwen et al., 2010).

In addition to the graphical model (Figure 2), the seasonal phenometrics in Hovsgol were extracted including the start and end of the growing season, the time of peak growing season, the length of the growing season, the amplitude of the growing season, the large and small integral metric of NDVI values, the rate of green up (left derivative), and the rate of senescence (right derivative) (Table 1). 


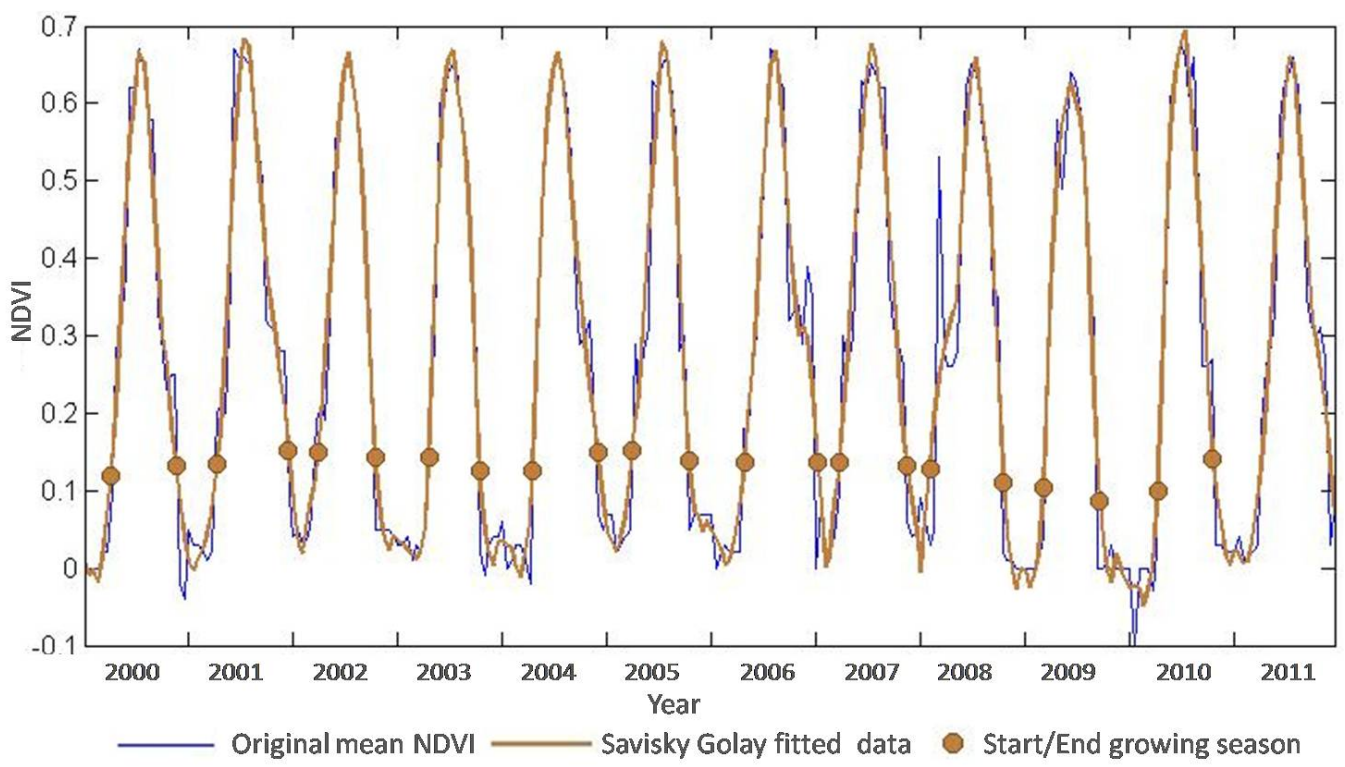

Figure 2. Graphical of the phenological metrics derived from NDVI time series; input NDVI time series data from January to December, 2000 to 2011; SG - Savitsky-Golay fitted curve with the points identifying the onset and end of growing season in Hovsgol, Mongolia

Table 1. Phenological metrics of vegetation growing in Hovsgol area extracted from NDVI time series data (January to December, 2000-2011) ${ }^{*}$

\begin{tabular}{ccccccccc}
\hline Year & Start & End & Length & Peak time & Peak NDVI & Ampl. & L.derive & R.derive \\
\hline 2000 & 113 & 295 & 182 & 193 & 0.66 & 0.63 & 0.15 & 0.10 \\
2001 & 115 & 313 & 198 & 199 & 0.67 & 0.65 & 0.15 & 0.08 \\
2002 & 113 & 292 & 179 & 195 & 0.65 & 0.61 & 0.16 & 0.12 \\
2003 & 118 & 284 & 166 & 196 & 0.66 & 0.61 & 0.17 & 0.13 \\
2004 & 116 & 299 & 182 & 199 & 0.66 & 0.62 & 0.15 & 0.09 \\
2005 & 119 & 291 & 171 & 204 & 0.66 & 0.62 & 0.13 & 0.13 \\
2006 & 129 & 306 & 177 & 206 & 0.67 & 0.63 & 0.14 & 0.09 \\
2007 & 102 & 300 & 198 & 201 & 0.65 & 0.60 & 0.10 & 0.10 \\
2008 & 105 & 294 & 189 & 201 & 0.65 & 0.61 & 0.11 & 0.11 \\
2009 & 105 & 294 & 189 & 201 & 0.64 & 0.62 & 0.10 & 0.12 \\
2010 & 123 & 302 & 179 & 204 & 0.68 & 0.65 & 0.18 & 0.10 \\
Mean & 114 & 297 & 183 & 200 & 0.66 & 0.62 & 0.14 & 0.11 \\
\hline
\end{tabular}

* TIMESAT derives (n-1) result time series data from $\mathrm{n}$ input data; Start and End are the onset and end of growing season (in Julian date); Length: length of growing season (day); Peak time: Time of peak growing season - NDVI max (in Julian date); Peak NDVI: maximum NDVI during growing season; Ampl.: Amplitude of the growing season $=$ NDVIpeak - NDVIbase, NDVIbase $=($ NDVIstart + NDVIend $) / 2$; L.derive and R.derive: the rate of green up, and the rate of senescence respectively.

\subsubsection{Analyzing of Spatial and Temporal Dynamics}

The temporal dynamics of vegetation in the study area was assessed based on the extracted phenological parameters from the time series data in relation to climate change. The monthly mean of air temperature and NDVI during growing season of each year were calculated to analyze the relationship between climate variations and vegetation dynamics. Missing air temperature data in 2000-2003 were estimated using the TVX regression model calibrated in the Rinchinlhumbe weather station with validation by data from the Hatgal weather station. 
The relationship between NDVI, air temperature, and precipitation was also derived using multiple linear regression models to explain the variation of NDVI caused by climatic variables.

To detect spatial heterogeneity due to climate change and other disturbances during 2000-2011, time series NDVI (NDVI $\mathrm{i}_{\mathrm{i}}$ ) data of peak growing season (in July) were employed to estimate a 2000-2011 coefficient of variation map $\left(\mathrm{COV}_{\mathrm{NDVI}}\right)$ (2.2) for which a Standard Deviation map $\left(\mathrm{STD}_{\mathrm{NDVI}}\right)(2.4)$, derived from NDVI time series data (00-11), was divided by the average NDVI during the study period (MEAN $\left.{ }_{\mathrm{NDVI}}\right)(2.3)$. The $\mathrm{COV}_{\mathrm{NDVI}}$ was calculated by each pixel over 12 year NDVI values (in July) for the entire area.

$$
\begin{gathered}
\operatorname{COV}_{\mathrm{NDVI}}=\mathrm{STD}_{\mathrm{NDVI}} / \mathrm{MEAN}_{\mathrm{NDVI}} \\
\text { In which: } \operatorname{MEAN}_{\mathrm{NDVI}}=\sum_{i=1}^{12} N D V I_{i} / 12 ; \\
\mathrm{STD}_{\mathrm{NDVI}}=\sqrt{\sum_{i=1}^{12}\left(N D V I_{i}-M E A N_{N D V I}\right)^{2} / 11} \\
\mathrm{i}-\text { Year }_{\mathrm{th}} .
\end{gathered}
$$

To detect site-specific vegetation cover anomalies in each year, the departure from mean NDVI method was applied for which the difference between yearly mean NDVI (MEAN ${ }_{\mathrm{NDVI}}$ ) from 2000 to 2011 and July mean NDVI values for each year $\left(\mathrm{NDVI}_{\text {year ith }}\right)$ were calculated as $(2.5)$.

\section{Results and Discussions}

$$
\mathrm{dNDVI}_{\text {year ith, mean }}=\mathrm{NDVI}_{\text {year ith }}-\mathrm{MEAN}_{\mathrm{NDVI}}
$$

\subsection{Phenological Metrics and Climate Variation}

The growing season in the area normally starts in late April (114 in Julian date) and ends in late October (297 in Julian date). The peak of the growing season is in the middle of July (200 in Julian date) (Table 1). The duration of the growing season in Hovsgol was unstable from 2000 to 2010 (Figure 3a). The longest growing seasons were witnessed in 2001 and 2007, 198 days each, while the 2003 growing season was the shortest with 166 days. However, the growing season in 2001 started and ended later than in 2007 and 2003. The fluctuation of the growing season length could be partially explained by the annual mean air temperature over 12 years as the length of the growing season was positively correlated with air temperature measured at the Rinchinlhumbe weather station $\left(R^{2}=0.5\right)$ (Figure 3b). The timing of the earlier growing season start from 2007 to 2009 (105 in Julian date) revealed phenological trends that very likely reflect responses to recent climate change of vegetation in the area (Table 1). In general, higher annual mean temperature resulted in the earlier growing season in Hovsgol area $\left(\right.$ Time $\left._{\text {start }}=-7.7 * \mathrm{~T}_{\text {air }}+212.6, \mathrm{R}^{2}=0.58\right)$. According to results of Walther et al. $(2002)$ and $\mathrm{Yu}$ et al. (2003), climate change studies in Europe, North America, and Central Asia revealed phenological trends that showed that the timing of the growing season is occurring earlier than ever before. A similar trend can be observed in the Hovsgol area including the earlier growth of plants in recent years (2007-2009).
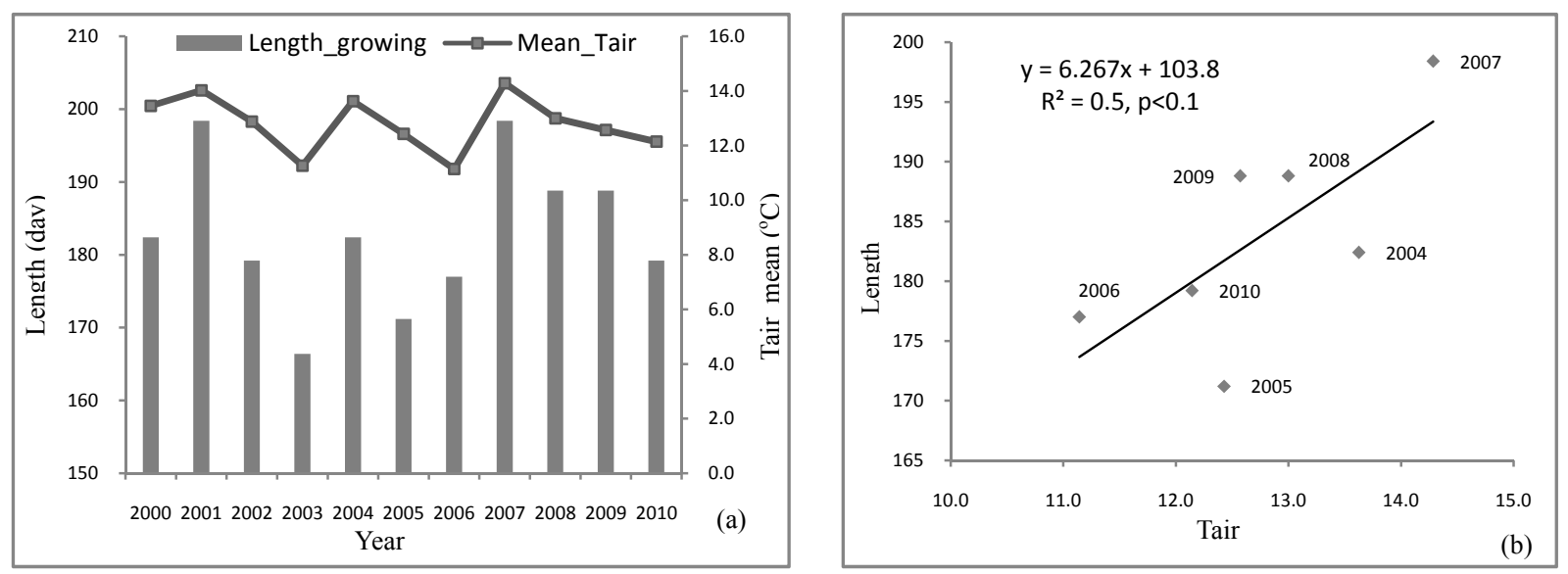

Figure 3. Length of growing season (day) and average air temperature (included the predicted $\mathrm{T}_{\text {air }}$ from January 2000- May 2004) (a); and correlation between length and mean air temperature of growing season (only available observed $\mathrm{T}_{\text {air }}$ data from 2004-2010 at Rinchinlhumbe) (b) 
In terms of growing rate, the high rates of green up (L. derive) were witnessed in almost all years, except from 2007 to 2009 . The rate of green up was much higher than that of senescence, average 0.14 and 0.1 , respectively (Table 1). Compared to the length of growing season and air temperature, the lower rate of green up and senescence seems to be the longer growing season with higher temperature $\left(\mathrm{R}^{2}=0.12-0.34\right)$. There is no evidence of relationship between precipitation and phenological variables. This is probably because of the strong influence by permafrost and soil moisture coupled with temperature rather than precipitation in the area.

\subsection{Seasonal NDVI and Climate Variation}

Temperature and NDVI have illustrated strong yearly cyclic variation for the past 12 years (Figure 4). Furthermore, the lack of lag between air temperature and NDVI also revealed that temperature is the limiting factor influencing vegetation greenness in the area. Maximum average temperature values measured at the Rinchinlhumbe weather station (2000-2011) in April, May, June, July, August, September, and October were $5.5^{\circ} \mathrm{C}, 13.2^{\circ} \mathrm{C}, 19^{\circ} \mathrm{C}, 20.6^{\circ} \mathrm{C}, 17.8^{\circ} \mathrm{C}, 11.7^{\circ} \mathrm{C}$, and $2.3^{\circ} \mathrm{C}$ respectively, with July being the highest. In relation to temperature, average NDVI values for the entire area in April, May, June, July, August, September, and October were $0.16,0.32,0.6,0.67,0.58,0.34$, and 0.2 respectively, with July being the highest as the full growing season. Compared with temperature and NDVI, precipitation values show a similar trend, but with larger variations. Total precipitation values in April, May, June, July, August, September, and October were 17, 34, 149, 222, 162, 100 , and $23 \mathrm{~mm}$ respectively, and the highest amount of monthly precipitation for each year appeared in June and July.

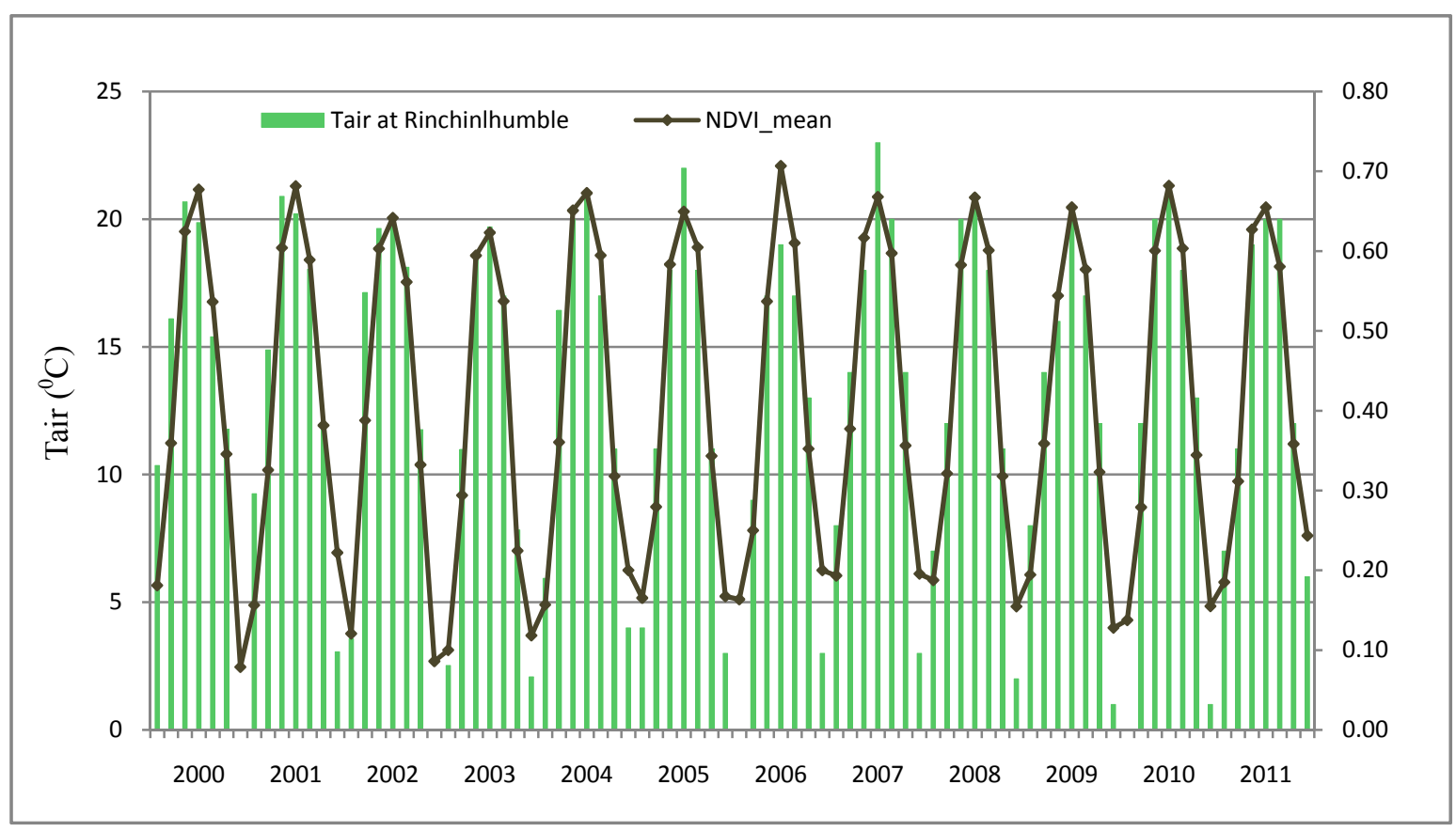

Figure 4. Monthly maximum mean air temperature measured (2004-2011) and estimated (January 2000- May 2004) at Rinchinlhumbe and mean NDVI for the entire area from April to October (2000-2011)

A positive high correlation between NDVI and independent temperature and precipitation variables $\left(\mathrm{R}^{2}=0.92\right.$, Adjusted $\mathrm{R}^{2}=0.91, \mathrm{p}<0.0001$, very low precipitation slope only significant at 0.001 level; no autocorrelation evidence between variables, $\mathrm{p}=0.1$ with Durbin Watson test) was described using the equation below (3.1). This result is consistent with other published studies showing that Larix forest growing in the area responds positively with summer warming (James, 2011).

$$
\text { NDVI }=0.025 * \text { Temperature }+0.002 * \text { Precipitation }+0.062
$$

The result reveals that about $90 \%$ of the variation in NDVI can be explained by changes in temperature and precipitation which indicates their important influence on vegetation growth in the area. However, other factors such as soil moisture related to permafrost, land cover types, and fire events are also interrelated with vegetation growth and require further examining in the area. 


\subsection{NDVI Temporal Heterogeneity}

The temporal forest heterogeneity in the study area showed a yearly variation. The high variation was witnessed in the onset of the growing season (late April) and the end of the growing season (late October) due to the green up and the senescence processes of vegetation, respectively, whereas the lowest variation occurred in July during the peak of the growing season (Figure 5). The high variation was also observed from late 2000 to 2003 and in late 2009, which may be due to the high frequency of fire occurrence reported during this period for which some locations were heavily affected (Farukh et al., 2009). In relation to climatic variables, however, there is evidence of the strong negative relationship between temperature during the growing season and NDVI heterogeneity $\left(\mathrm{COV}_{\mathrm{NDVI}}=0.001 * \mathrm{Tair}^{2}-0.065 * \mathrm{Tair}+1.125, \mathrm{R}^{2}=0.77\right)$. In other words, lower temperature in the early and late periods of the growing season is correlated with more vegetation dynamics.

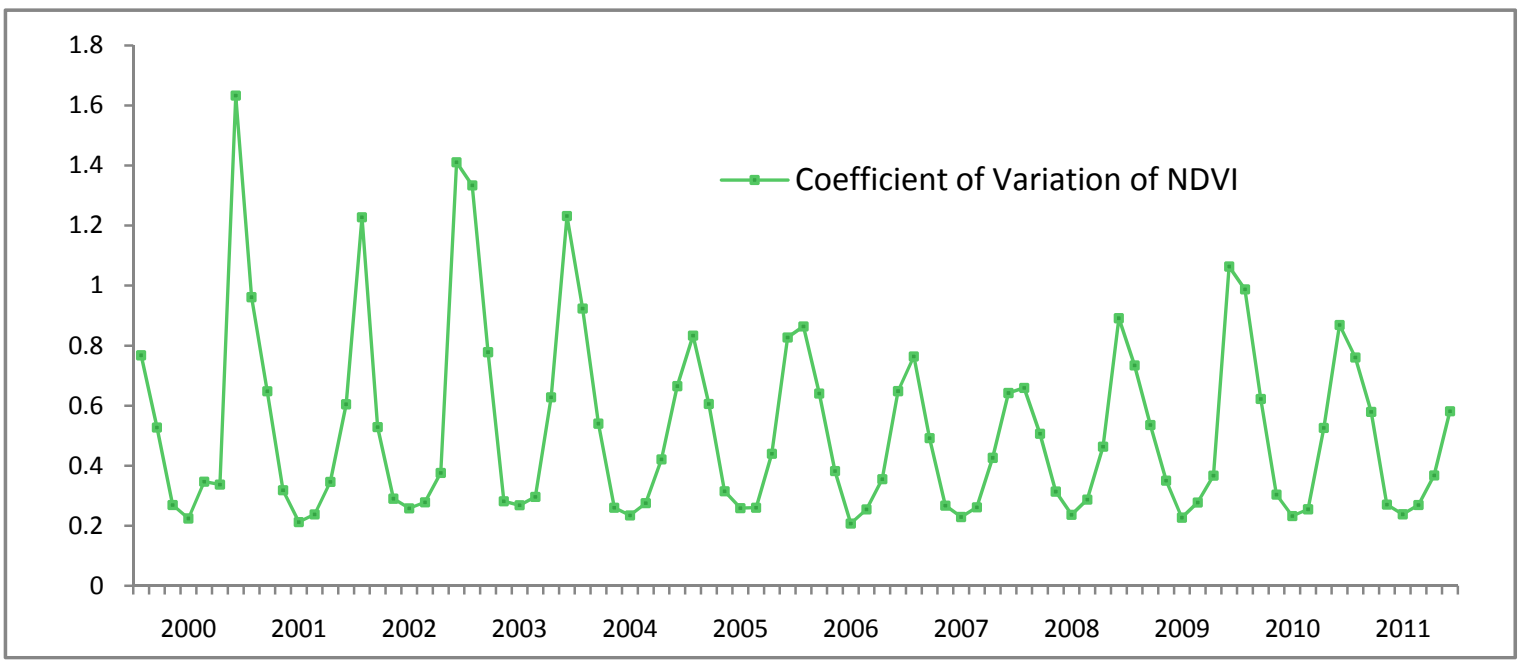

Figure 5. Temporal heterogeneity of NDVI in Hovsgol forest during the growing season from April to October (2000-2011) - COV was derived from NDVI values of 150 random samples within the area during the growing season over 12 years

\subsection{Spatial Pattern of Annual NDVI Changes}

Distribution of the high NDVI variation is shown in the western part of the Hovsgol Lake, including Darhad valley (Figure 6). According to the land cover map in 2005 (http://daac.ornl.gov/), the high variation areas are mainly covered by grassland and open shrublands. The result infers that these areas were highly affected by disturbances from 2000 to 2011.

In order to develop support for the findings of temporal heterogeneity in the area, the departure from average July NDVI images were derived (Figure 7). The below average values stand for negative changes, while above average values correspond to positive vegetation growth. Forest areas in 2002, 2003, 2005, 2007, 2008, 2009, and 2011 experienced severe growth conditions as illustrated by the large area of below average NDVI. On the other hand, a high proportion of positive changes were witnessed in 2000, 2001, 2004, 2006, and 2010 as a result of vegetation responses following a heavy disturbance event (i.e. severe condition in 2002, 2003 following by vegetation regrowth in 2004). Post disturbance landscapes caused by fire or climate change are typically characterized by a high degree of spatial variability immediately following the disturbance due to the response and distribution of biotic and abiotic factors (Liu et al., 2009; Van Leeuwen et al., 2010). This statement may be correct in this study. However, in order to fully understand the effects of climate change and other disturbances on spatial variation, land cover type, species components, and biophysical variables should be investigated and considered interrelated.

Finally, the average vegetation growth dynamics over 12 years was assessed based on the July 2000 NDVI image and July 2011 NDVI image. Overall, the large amount of vegetation negatively responds to growth conditions over 12 years, particularly in Darhad valley with $15-35 \%$ of losses being greenness (Figure 8 ). 


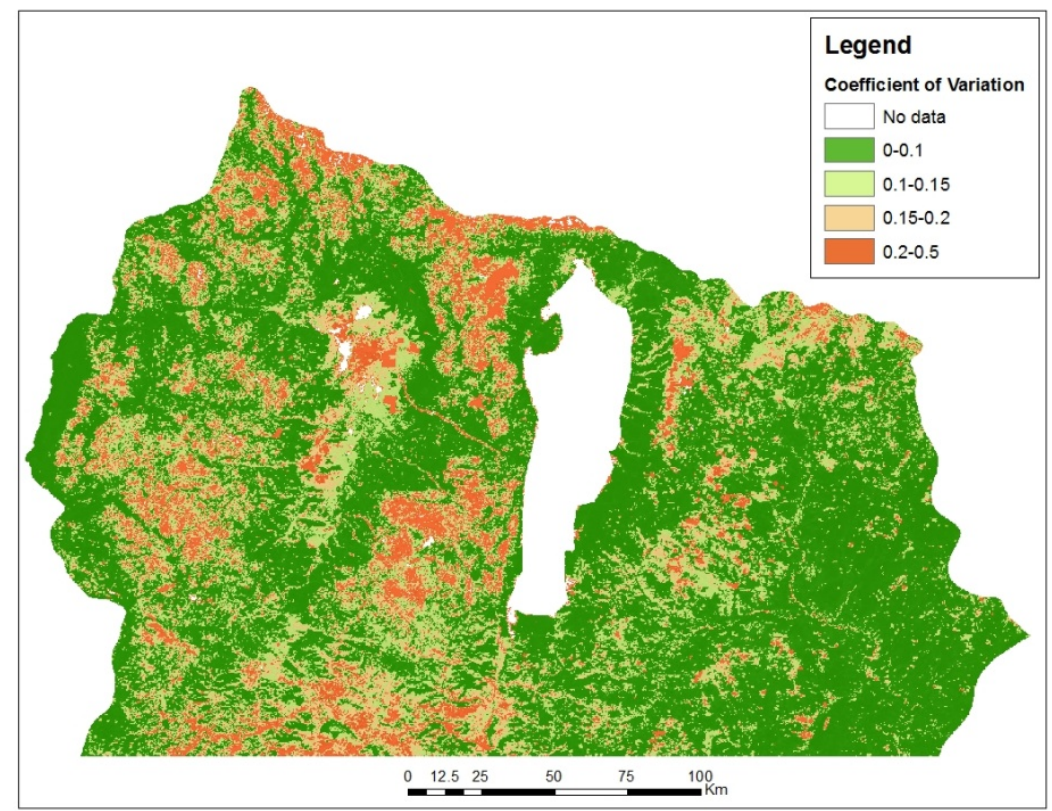

Figure 6. Coefficient of variation of NDVI values over 12 years (2000-2011) in Hovsgol area

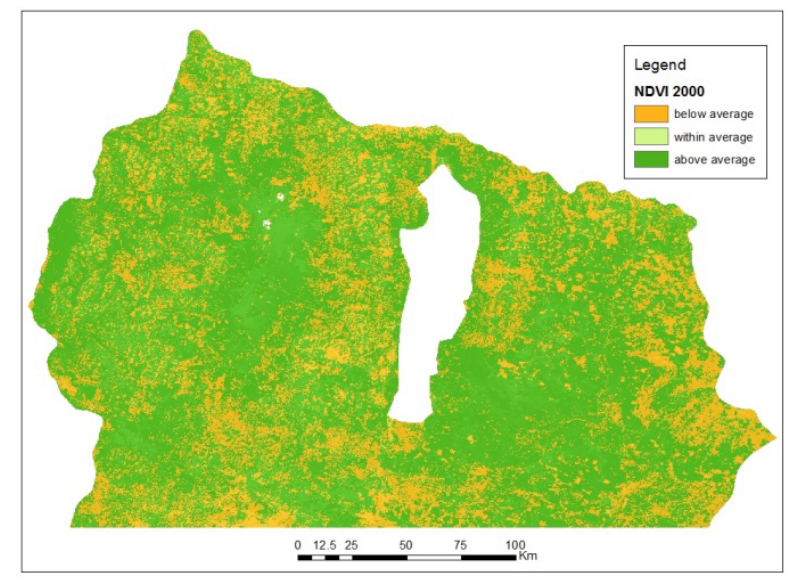

2000

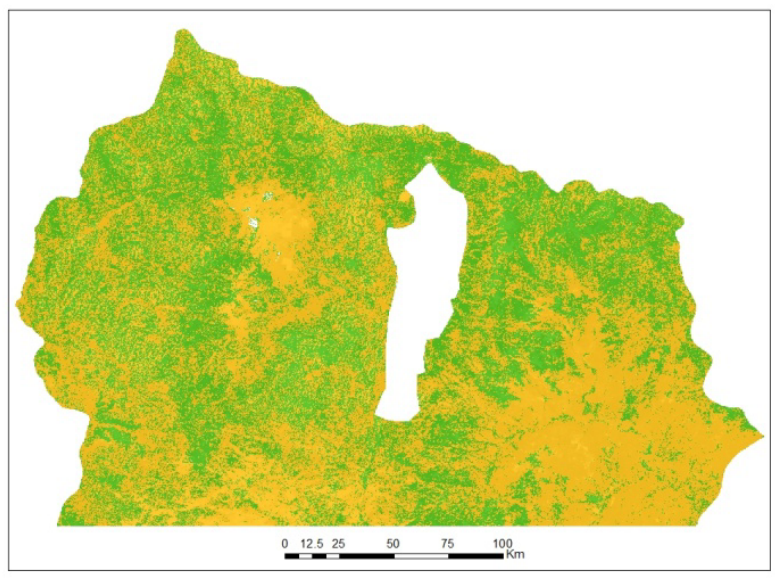

2002

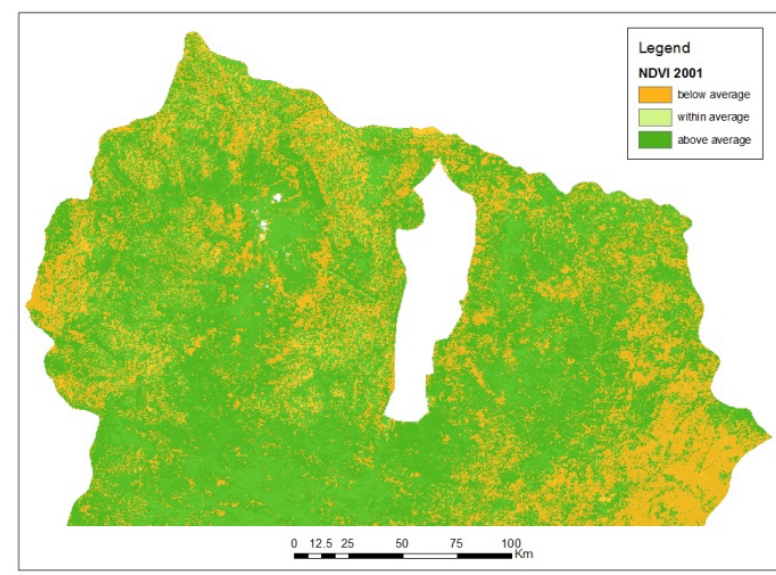

2001

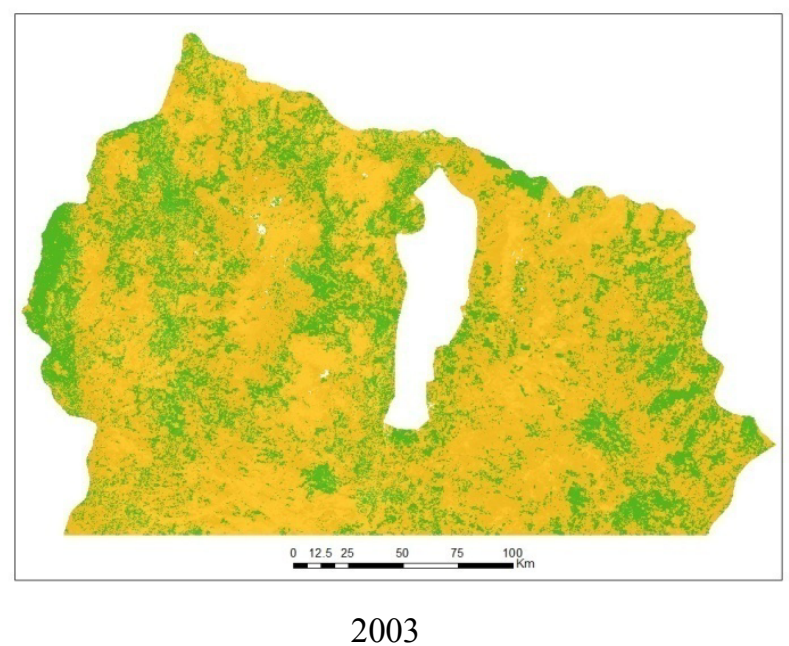




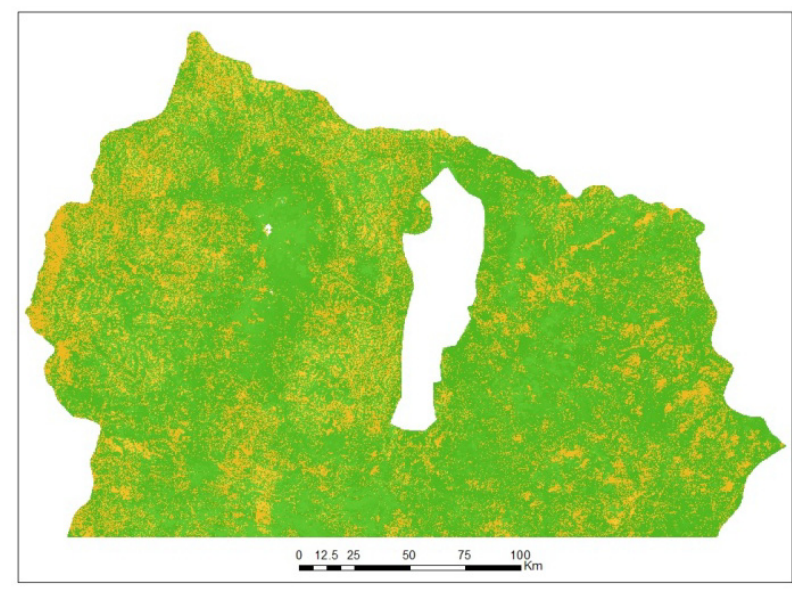

2004

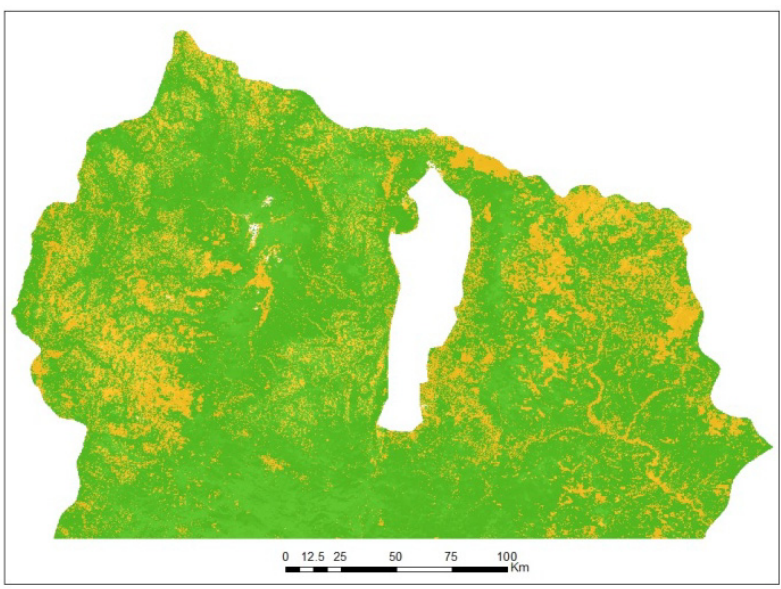

2006

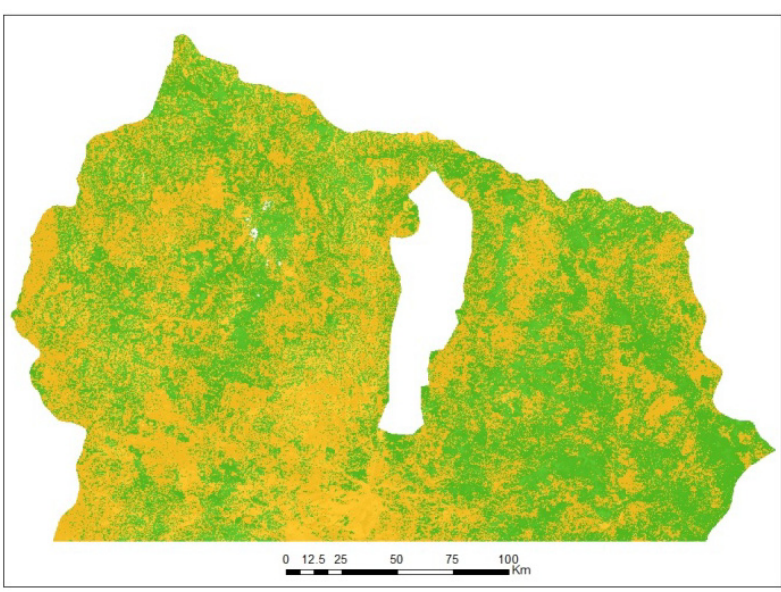

2008
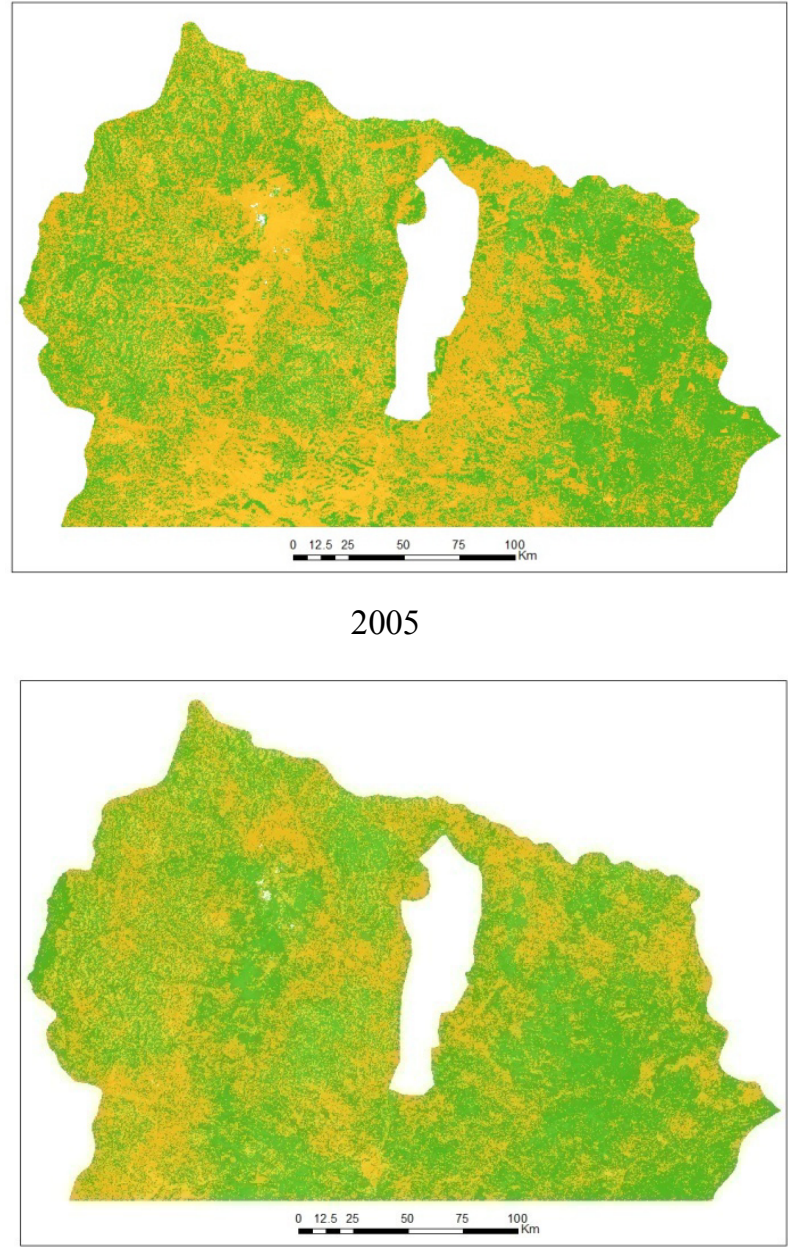

2007

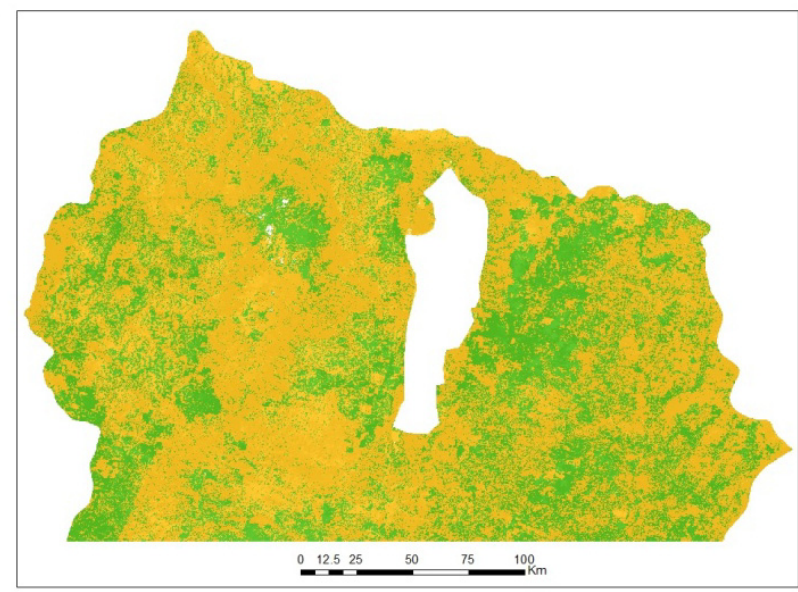

2009 


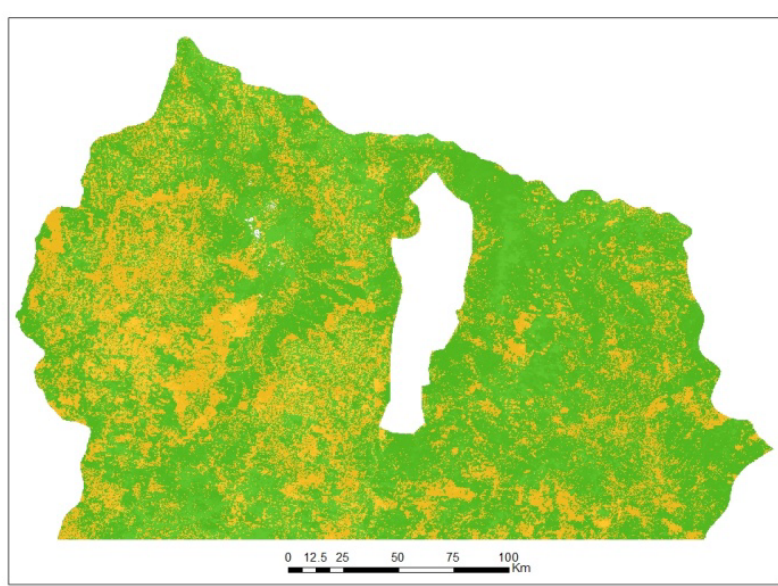

2010

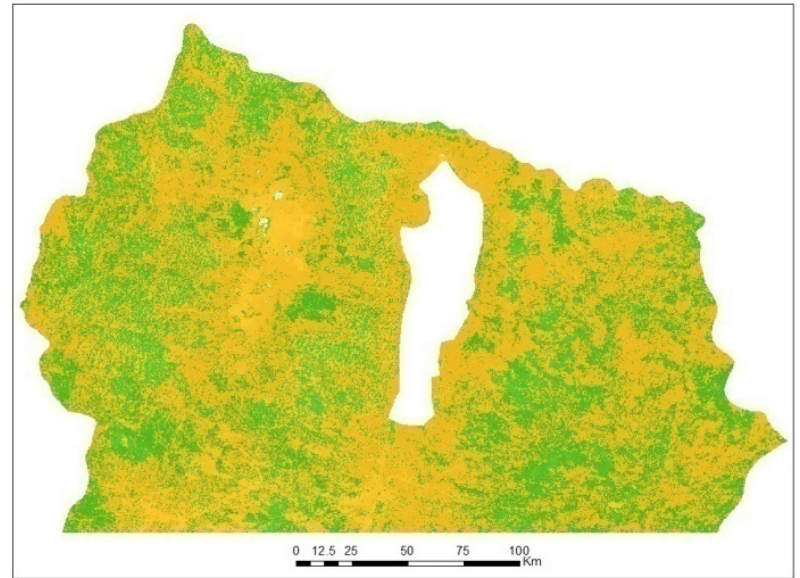

2011

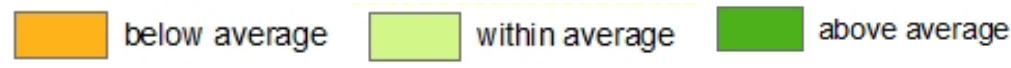

Figure 7. Departure from average July NDVI images (2000-2011), Hovsgol, Mongolia

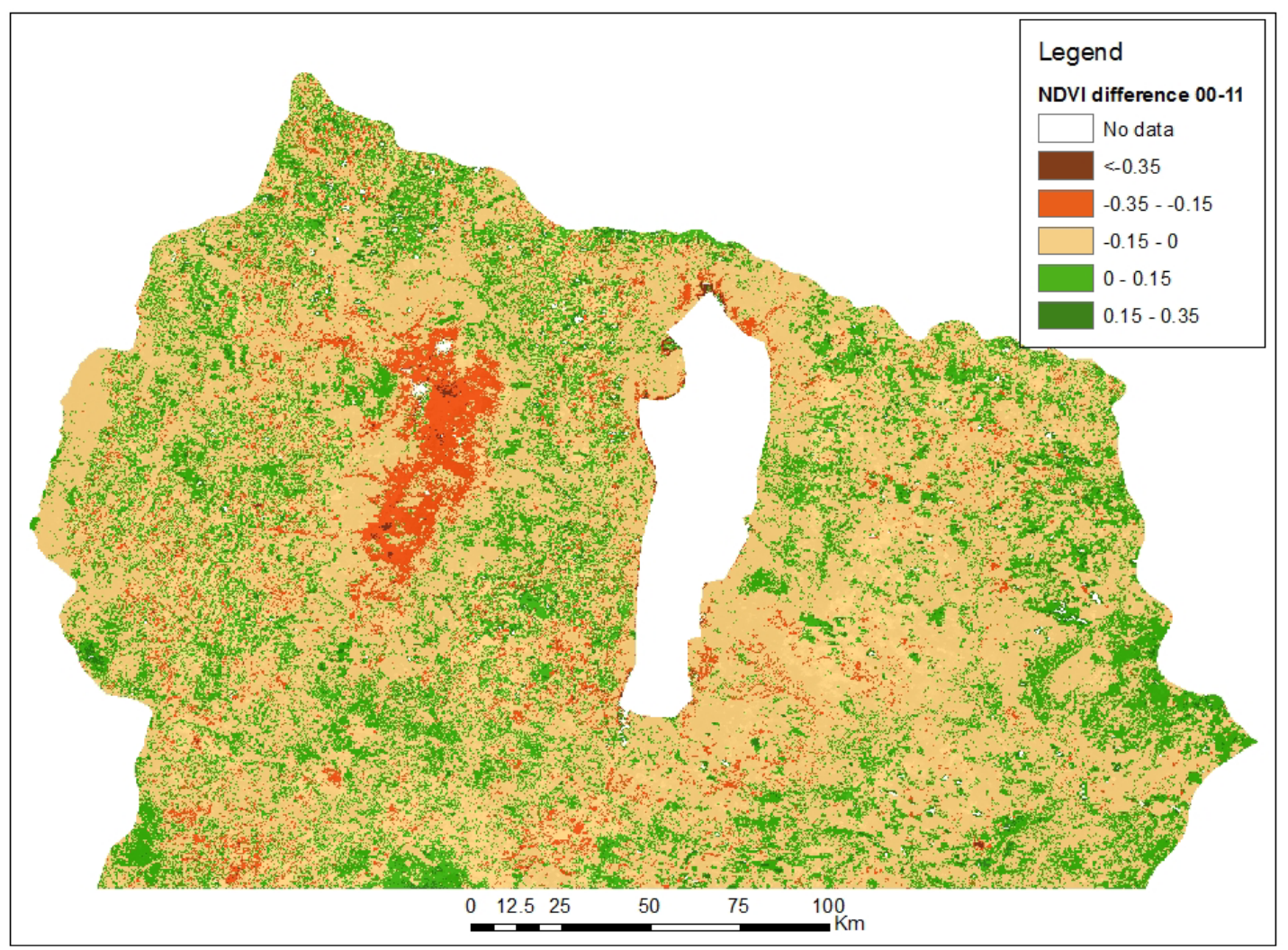

Figure 8. NDVI difference image of Hovsgol, Mongolia between 2000 and 2011

\section{Conclusion and Future Work}

Remotely sensed time series data from the MODIS sensor were used to estimate air temperature at the pixel level, extract the phenological metrics, characterize the temporal and spatial dynamics of vegetation, and evaluate the effects of climate change on vegetation in the Hovsgol area. Air temperature can be well estimated using the TVX regression model with a mean absolute error of $2.2^{\circ} \mathrm{C}$. The growing season in the area normally starts in 
late April and ends in late October, and the peak of the growing season is reached in July. However, due to climate change and other disturbances, the length of the growing season among the observed years fluctuated between 166 and 198 days. The higher temperature results in a longer and earlier growing season (correlation between the length and temperature, the timing start and temperature with $\mathrm{R}^{2}=0.5$ and 0.58 respectively). Precipitation, on the other hand, was insignificant with phenological variables dynamics.

Temperature and NDVI have illustrated strong yearly cyclic variation for the past 12 years. The highest mean air temperature during the growing season was witnessed in July at $20.6^{\circ} \mathrm{C}$ and the lowest was in October at $2.3^{\circ} \mathrm{C}$. There was a strongly positive relationship between NDVI, air temperature, and precipitation during the growing season. Air temperature; however, seems to be the main factor contributing to NDVI variation in the area. In order to have strong evidence of climate change effects on vegetation growth, longer time series of satellite data such as NOAA AVHRR should be included to increase the observed timeframe probably up to 30 years. This is entirely possible as available daily NOAA AVHRR data can be downloaded for the area.

A high degree of NDVI variation was estimated in early April and late October of the growing seasons of 2000, 2001, 2002, 2003, and 2009. This may show the degree of vegetation response post disturbances in previous months and years, except for 2000 and 2001, as the spatial pattern of NDVI in July 2002, 2003, 2005, 2007, 2008, 2009, and 2011 illustrated the high level of degradation departing from average NDVI. However, identifying of disturbed areas by wildfire, logging, or climate change in specific and longer timeframes will be necessary to fully explain the interrelationship between disturbance events and vegetation responses. Finally, analysis of spatio-temporal heterogeneity using NDVI time series over 12 years also indicated that some areas with high variation of vegetation growth, particularly in the western part of the Hovsgol lake and Darhad valley.

Further explanations of climatic change and other disturbances such as wildfires and deforestation effects on vegetation dynamics and recovery will require the consideration of land use, land cover types, vegetation community, and structure for a certain time period. Because of remote sensing tool capabilities, these types of investigations can be conducted spatially and temporally by different sensors and scales, providing the opportunity to understand vegetation response after disturbances, especially following wildfires in Mongolia.

\section{Acknowledgement}

This study was funded by Vietnam International Education Development Program and Department of Geography and Planning, University of Saskatchewan scholarships. The authors acknowledge the anonymous reviewers, Jordon Steeg for their valuable comments and suggestions for improving this manuscript.

\section{References}

Banzragch, N., J. Scott Greene, \& Clyde, E. Goulden. (2007). Trends in extreme daily precipitation and temperature near lake Hovsgol, Mongolia. International Journal of Climatology, 27, 341-347. http://dx.doi.org/10.1002/joc.1404

Batima, P., Natsagdorj, L., Gombluudev, P., \& Erdenetsetseg, B. (2005). Observed climate change in Mongolia. Assess Imp Adapt Clim Change Work Pap, 12, 1-26.

Casady, G. M., van Leeuwen, W. J. D., \& Marsh, S. E. (2009). Evaluating post-wildfire vegetation regeneration as a response to multiple environmental determinants. Environmental Modeling and Assessment, 15(5), 295-307. http://dx.doi.org/10.1007/s10666-009-9210-x

Dulamsuren, C., Hauck, M., \& Leuschner, C. (2010). Recent drought stress leads to growth reductions in Larix sibirica in the western Khentey, Mongolia. Global Change Biology, 16(11), 3024-3035.

Erdenesaikhan, N. (2002). Time series satellite data analysis for assessment of vegetation cover of Mongolia. ESRI's 22nd Annual User Conference.

Farukh, M. A., Hayasaka, H., \& Mishigdorj, O. (2009). Recent Tendency of Mongolian Wildland Fire Incidence: Analysis Using MODIS Hotspot and Weather Data. Journal of Natural Disaster Science, 31(1), 23-33. http://dx.doi.org/10.2328/jnds.31.23

Guo, X., Wilmshurst, J., McCanny, S., Fargey, P., \& Richard, P. (2004). Measuring Spatial and Vertical Heterogeneity of Grasslands using Remote Sensing Techniques. Journal of Environmental Informatics, 1726-2135, 24-32.

IFFN. (1999). Forest and Steppe fire Monitoring in Mongolia using Satellite Remote sensing. International Forest Fire News (IFFN), 21, 71-74.

IFFN. (2007). The Forest Fire Situation in Mongolia. International Forest Fire News (IFFN), 3, 46-66.

James, T. M. (2011). Temperature sensitivity and recruitment dynamics of Siberian larch (Larix sibirica) and Siberian spruce (Picea obovata) in northern Mongolia's boreal forest. Forest Ecology and Management. 
Jonsson, P., \& Eklundh, L. (2002). Seasonality extraction by function fitting to time-series of satellite sensor data. Geoscience and Remote Sensing, IEEE Transactions on, 40(8), 1824-1832.

Jonsson, P., \& Eklundh, L. (2004). TIMESAT--a program for analyzing time-series of satellite sensor data. Computers \& Geosciences, 30(8), 833-845. http://dx.doi.org/10.1016/j.cageo.2004.05.006

Leon, J. R. R., van Leeuwen, W. J. D., \& Casady, G. M. (2012). Using MODIS-NDVI for the Modeling of Post-Wildfire Vegetation Response as a Function of Environmental Conditions and Pre-Fire Restoration Treatments. Remote Sensing, 4(3), 598-621. http://dx.doi.org/10.3390/rs4030598

Liu, S., Mo, X., Zhao, W., Naeimi, V., Dai, D., Shu, C., \& Mao, L. (2009). Temporal variation of soil moisture over the Wuding River basin assessed with an eco-hydrological model, in-situ observations and remote $\begin{array}{lllll}\text { sensing. Hydrology and Earth System } & \text { Sciences, } & \text { 13(7), } & \text { 1375-1398. }\end{array}$ http://dx.doi.org/10.5194/hess-13-1375-2009

Magsar Erdenetuya, S. K. (1999). Fire Monitoring in Mongolia. GISdevelopment.net, ACRS, Poster Session 4.

Murray, M. (2004). Dynamics of Biodiversity Loss and Permafrost Melt in Lake Hovsgol National Park, Mongolia. Hovsgol GEF/WB Project TF028988, Geo-Ecology Institute 301, Mongolia.

Nieto, H. C., Sandholt, I., Aguado, I., Chuvieco, E., \& Stisen, S. (2011). Air temperature estimation with MSG-SEVIRI data: Calibration and validation of the TVX algorithm for the Iberian Peninsula. Remote Sensing of Environment, 115(1), 107-116. http://dx.doi.org/10.1016/j.rse.2010.08.010

Prihodko, L., \& Goward, S. N. (1997). Estimation of air temperature from remotely sensed surface observations. Remote Sensing of Environment, 60(3), 335-346. http://dx.doi.org/10.1016/S0034-4257(96)00216-7

Ravenscroft, C., Scheller, R. M., Mladenoff, D. J., \& White, M. A. (2010). Forest restoration in a mixed-ownership landscape under climate change. Ecological Applications, 20(2), 327-346. http://dx.doi.org/10.1890/08-1698.1

Sanjaa Tuya, C. P. G., \& Yoshiaki Honda. (2002). Fire detection technology in Mongolia. Hazard Mitigation and Disaster management.

Sato, T., \& Kimura, F. (2006). Regional climate simulations to diagnose environmental changes in Mongolia. Bull Terr Environ Res Cent Univ Tsukuba, 7, 59-69.

USGS. (2011). MODIS reprojection tool user's manual. Land Processes DAAC, USGS Earth Resouces Observation and Science (EROS) Center, 4.1.

Van Leeuwen, W. J. (2008). Monitoring the effects of forest restoration treatments on post-fire vegetation recovery with MODIS multitemporal data. Sensors, 8(3), 2017-2042. http://dx.doi.org/10.3390/s8032017

Van Leeuwen, W. J. D., Casady, G. M., Neary, D. G., Bautista, S., Alloza, J. A., Carmel, Y., ... Barron J. O. (2010). Monitoring post-wildfire vegetation response with remotely sensed time-series data in Spain, USA and Israel. International Journal of Wildland Fire, 19(1), 75-93. http://dx.doi.org/10.1071/WF08078

Vancutsem, C., Ceccato, P., Dinku, T., \& Connor, S. J. (2010). Evaluation of MODIS land surface temperature data to estimate air temperature in different ecosystems over Africa. Remote Sensing of Environment, 114(2), 449-465. http://dx.doi.org/10.1016/j.rse.2009.10.002

Veraverbeke, S., Gitas, I., Katagis, T., Polychronaki, A., Somers, B., \& Goossens, R. (2011). Assessing post-fire vegetation recovery using red - near infrared vegetation indices: Accounting for background and vegetation variability. ISPRS Journal of Photogrammetry and Remote Sensing, 68, 28-39.

Walther, G. R., Post, E., Convey, P., Menzel, A., Parmesan, C., Beebee, T. J. C., et al. (2002). Ecological responses to recent climate change. Nature, 416(6879), 389-395. http://dx.doi.org/10.1038/416389a

Xiaohui Yang, X. G. (2011). Remote sensing of Vegetation Productivity in Northern Ecosystems: NDVI change figures and maps. Report for Parks Canada.

Yu, F., Price, K. P., Ellis, J., \& Kastens, D. (2004). Satellite observations of the seasonal vegetation growth in central Asia: 1982-1990. Photogrammetric engineering and remote sensing, 70(4), 461-469.

Yu, F., Price, K. P., Ellis, J., \& Shi, P. (2003). Response of seasonal vegetation development to climatic variations in eastern central Asia. Remote Sensing of Environment, 87(1), 42-54. http://dx.doi.org/10.1016/S0034-4257(03)00144-5

Zhang, C., Guo X., Wilmshurst, J. F., \& Crump, S. (2008). Monitoring Temporal Heterogeneity in a Protected Mixed Prairie Ecosystem Using 10 day NDVI Composite. Prairie Forum, 33(1), 145-166. 